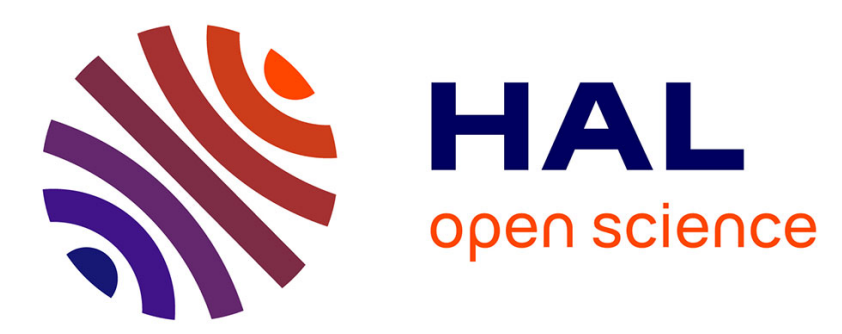

\title{
The role of cyclic slip localization in fatigue damage of materials
}

\author{
J. Polák, S. Degallaix, G. Degallaix
}

\section{To cite this version:}

J. Polák, S. Degallaix, G. Degallaix. The role of cyclic slip localization in fatigue damage of materials. Journal de Physique IV Proceedings, 1993, 03 (C7), pp.C7-679-C7-684. 10.1051/jp4:19937107 . jpa00251724

\section{HAL Id: jpa-00251724 https://hal.science/jpa-00251724}

Submitted on 1 Jan 1993

HAL is a multi-disciplinary open access archive for the deposit and dissemination of scientific research documents, whether they are published or not. The documents may come from teaching and research institutions in France or abroad, or from public or private research centers.
L'archive ouverte pluridisciplinaire HAL, est destinée au dépôt et à la diffusion de documents scientifiques de niveau recherche, publiés ou non, émanant des établissements d'enseignement et de recherche français ou étrangers, des laboratoires publics ou privés. 


\title{
The role of cyclic slip localization in fatigue damage of materials
}

\author{
J. POLÁK, S. DEGALLAIX* and G. DEGALLAIX*
}

Institute of Physical Metallurgy, Academy of Sciences, Žižkova 22, 61662 Brno, Czech Republic " now at L.M.L., URA 1441 du CNRS, Ecole Centrale de Lille, Cité Scientifique, BP. 48, 59651 Villeneuve d'Ascq cedex, France

\begin{abstract}
Cyclic slip localization is demonstrated in several classes of materials as copper single crystals, polycrystals and in a duplex austenitic-ferritic stainless steel, in measuring the cyclic stress-strain response, studying the surface relief evolution and the internal dislocation structures. The characteristic structure of the persistent slip bands accommodating high local plastic strain amplitude is correlated with the extrusion/intrusion formation on the surface, which results in fatigue crack nucleation, short crack growth, dominant crack formation, its growth and fracture. These stages represent the physical manifestation of the fatigue damage.
\end{abstract}

\section{Introduction}

Inhomogeneous distribution of the cyclic strain has been detected as early as the first microscopic observations of the fatigued Swedish iron were performed in 1903 by Ewing and Humfrey [1]. Another indication of the localized cyclic plastic straining was the observation of extrusions and intrusions on the surface of several fatigued materials by Forsyth [2].The formulation of the Manson-Coffin law revealed the importance of the cyclic plastic strain in fatigue and more interest has been devoted to its accommodation and distribution in the material.

The observations of the surface slip markings in fatigued materials revealed inhomogeneous distribution of the slip bands and more pronounced surface relief in comparison with monotonic straining. The reappearance of these slip bands after the interruption of cycling, the repolish of the surface, and after new cycling, lead to the name of persistent slip bands (PSBs). The mapping of internal dislocation structures in simple materials revealed specific structures of these bands which allowed to create models of localized plastic straining leading to the crack nucleation [3].

The subject of the present paper is to summarize the diversified knowledge concerning cyclic slip localization in crystalline materials and to demonstrate, using number of examples, the role of cyclic slip localization in fatigue damage, preferentially in the domain of crack nucleation and early growth.

\section{Slip localization in single crystals}

In cyclic straining of single crystals having polished surface, the cyclic slip localization can be detected with an uninstrumented eye. The slip bands parallel to the primary slip plane start to appear on the surface shortly before the stress amplitude saturates. The magnified picture in the scanning electron microscope (SEM) reveals the slip markings in the form of extrusions and intrusions. Figure 1 shows the SEM micrograph of the upper surface of a fatigued copper single crystal, oriented for single glide. Since the primary Burgers vector emerges at a high angle, the relief on this surface is most pronounced. A macroband and several individual PSBs appear while the rest of the surface is without any traces of slip. The lowest individual PSB, which ends within the micrograph, is characterized by alternating tongue-like extrusions and intrusions. Well developed individual PSBs have band-like extrusions and a crack along them. The macroband consists of individual PSBs close each to the other whose band-like extrusions overleap, are bent, and give rise to a net protrusion. The cracks within the macroband are hidden by numerous overlapping extrusions. 
The dislocation structure of a macro-PSB is shown in Fig. 2 in a section parallel to the cross-glide plane. Macro-PSB is embedded in a matrix structure which consists of alternating dislocation bundles and channels occupying approximately equal volume fractions. The macroband consists either of the closely spaced individual PSBs with the typical ladder structure, or of a true macroband with the ladder structure only on the boundary with the matrix and the cell structure in the interior of the macroband.

The cyclic slip localization in single crystal has been detected by measuring the hysteresis loop changes $[4,5]$. The evolution of the shape of the hysteresis loop during cycling of a copper single crystal oriented for single glide is shown in Fig. 3. The shape changes were characterized by the loop shape parameter $V_{H}$ and the hardening coefficient $\mathrm{H}$ in the tensile tip of the loop. $\mathrm{V}_{\mathrm{H}}$ is the ratio of the loop area to the area of a parallelogram drawn around the loop by extending elastic lines in tension and compression and drawing another two lines parallel to the $x$-axis in the extremal points of the loop.

Figure 4 shows the shear stress amplitude $\tau_{\mathrm{a}}$ simultaneously with $\mathrm{V}_{\mathrm{H}}$ and $\mathrm{H}$ plotted vs number of cycles in constant plastic strain amplitude cycling. $\mathrm{VH}_{\mathrm{H}}$ decreases and $\mathrm{H}$ increases during hardening, however, when first PSBs start to appear on the surface $V_{H}$ reaches minimum, $H$ maximum and both start to change in the opposite directions. The minimum of $\mathrm{V}_{\mathrm{H}}$, or maximum of $\mathrm{H}$ can be used for the detection of the start of the strain localization in single crystals $[4,5]$.

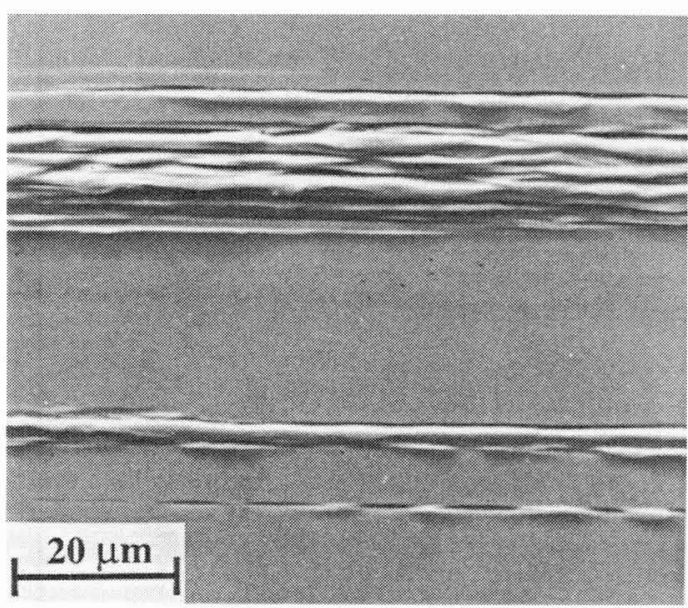

Fig. 1. SEM micrograph of the surface of fatigued copper single crystal.

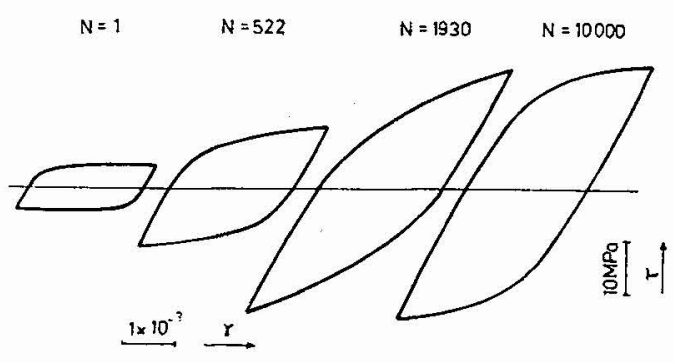

Fig. 3. Hysteresis loop of the fatigued copper single crystal; $\gamma_{\text {ap }}=1.2 \times 10^{-3}$.

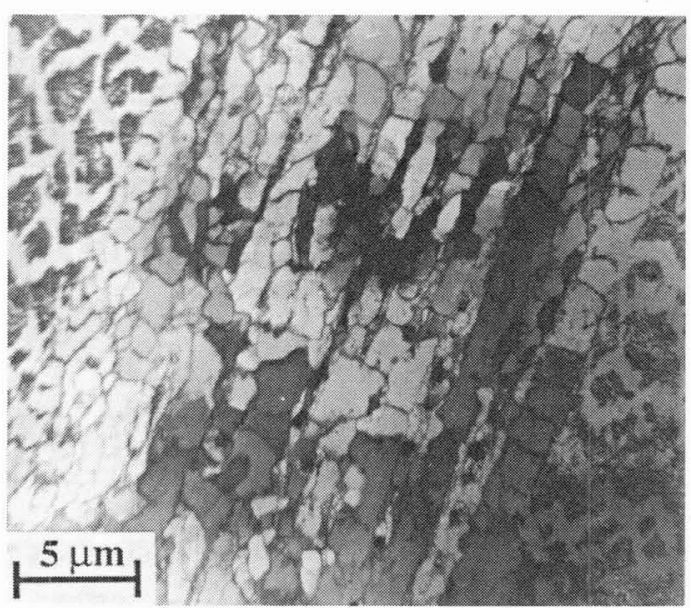

Fig. 2. TEM micrograph of a macro-PSB in a copper single crystal (foil parallel to the cross glide plane).

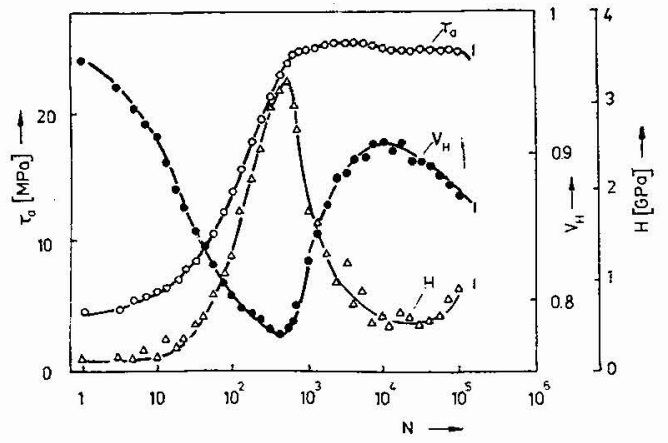

Fig. 4. Plot of $\tau_{\mathrm{ap}}, \mathrm{V}_{\mathrm{H}}$ and $\mathrm{H}$ in cycling copper single crystal with $\gamma_{\text {ap }}=4 \times 10^{-3}$. 


\section{Slip localization in polycrystals}

Polycrystalline materials consist of a great number of grains and compatibility conditions modify the stress state of individual grains. It becomes slightly different from that which is deduced from the direction of external force, cross section and grain orientation. When plastic strain is low, in a majority of grains only a single slip system is active. Figure 5 shows the surface of work-hardened polycrystalline copper subjected to low amplitude cyclic straining. There are two active slip systems and two nearly independent systems of PSBs in which a pronounced surface relief arises. The individual PSBs are very thin, with extrusions, intrusions and cracks along them. In the second slip system, high extrusions, which are bent towards the original surface, are apparent.

The dislocation structure of polycrystalline copper cycled with plastic strain amplitude $8 \times 10^{-4}$ in a grain sectioned parallel to the cross glide plane is shown in Fig. 6. The ladder structure of PSB embedded in a matrix is nearly identical with the dislocation structure of an individual PSB in single crystal $[5,6]$. Numerous PSBs can be observed in polycrystalline copper cycled with medium plastic strain amplitudes $\left(\sim 10^{-3}\right)$ both in the interior and on the surface.

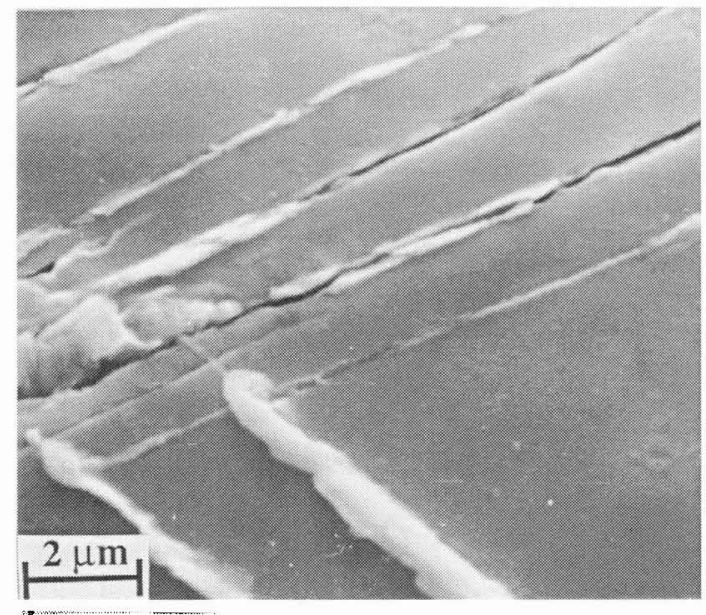

Fig. 5. Surface of the work-hardened and fatigued polycrystalline copper (SEM); $\gamma_{a p}=4 \times 10^{-3}$.

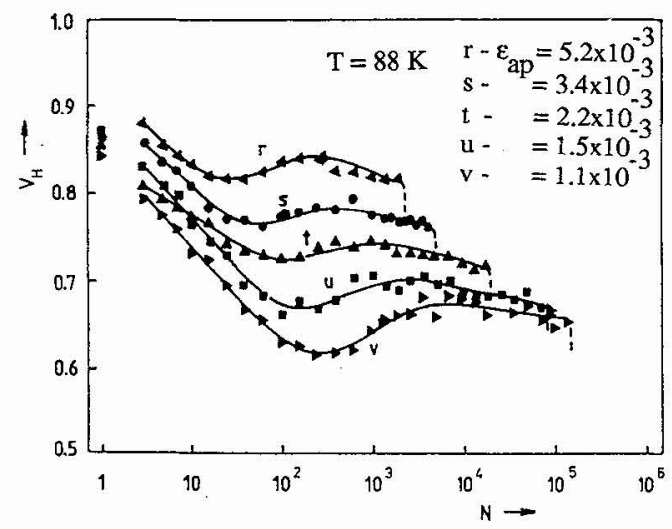

Fig. 7. Loop shape parameter in polycrystalline copper cycled at $88 \mathrm{~K}$ vs number of cycles.

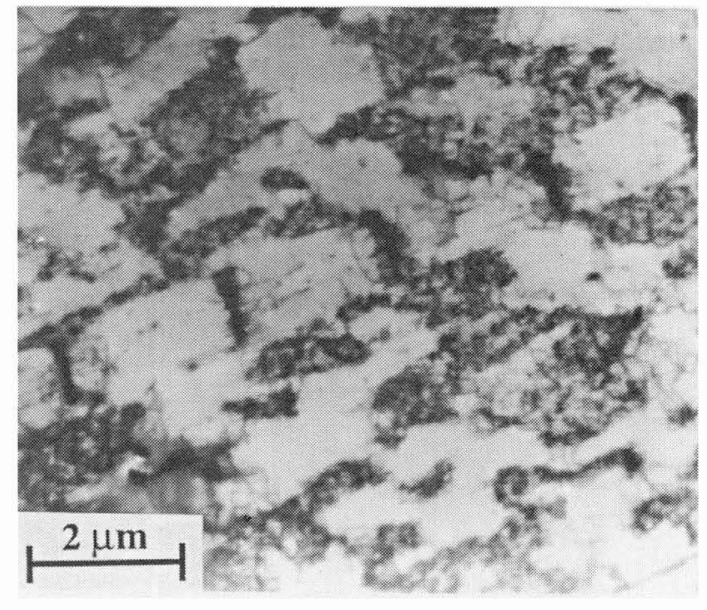

Fig. 6. TEM micrograph of polycrystalline copper cycled with $\varepsilon_{\mathrm{a}}=8 \times 10^{-4}$.

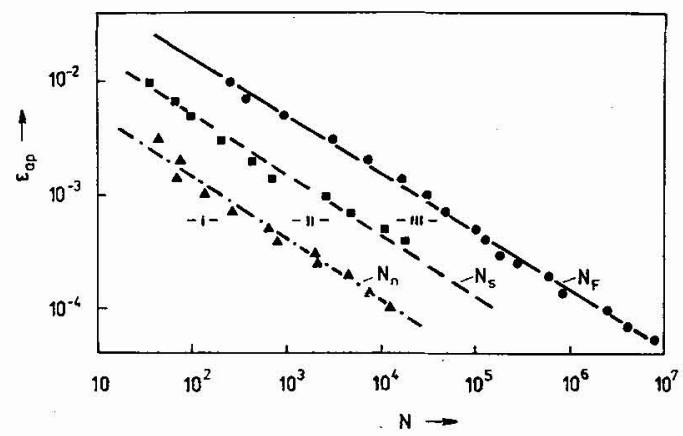

Fig. 8. Fatigue mechanism map of polycrystalline copper at room temperature. 
Hysteresis loop changes in polycrystalline copper can be also used to detect the cyclic slip localization $[7,8]$. Figure 7 shows the plot of $\mathrm{V}_{\mathrm{H}}$ parameter vs number of cycles in constant plastic strain amplitude loading at the temperature $88 \mathrm{~K}$ at which the localization is most pronounced. In analogy with single crystals the minimum of $V_{H}$ could be ascribed to the start of strain localization and corresponding number of cycles is denoted by $\mathrm{N}_{n}$ (PSB nucleation). When $\mathrm{V}_{\mathrm{H}}$ reaches local maximum, the crystal is saturated with PSBs and stress amplitude becomes saturated, too (number of cycles is denoted by $\mathrm{N}_{\mathrm{S}}$ - saturation). Cyclic plastic strain is concentrated to the existing PSBs and repeated local high amplitude straining in a quasi-elastically strained matrix results in crack initiation [9]. Nucleated short crack starts to grow, the dominant crack is formed and its propagation results in fatigue fracture in $N_{f}$ cycles. The plot of $N_{n}, N_{S}$ and $N_{f}$ vs $\varepsilon_{a p}$ delineates the areas of different fatigue mechanisms. The fatigue mechanism map for room temperature cycling of polycrystalline copper is shown in Fig. 8. In this map three regimes I to III are shown which correspond to the regime of the homogeneous cyclic plastic straining (I), to the regime of cyclic plastic strain localization (II) and to the regime of repeated cyclic plastic straining limited to PSBs (III) in which fatigue cracks are nucleated and start growing.

\section{Slip localization in structural materials}

Numerous classes of structural materials are adopted for design of machines and structures. Most of them are crystalline materials, however, a proportion of amorphous, polymeric and composite materials are used, too. An interesting material representing a natural composite is a duplex austenitic-ferritic stainless steel. Various modifications of this material become to be widely used in several branches of the industry primarily due to high mechanical properties combined with a high corrosion resistance. Duplex stainless steel consists of approximately equal fractions of b.c.c. ferrite and f.c.c. austenite. In a wrought material both components have the form of small grains (10-20 $\mu \mathrm{m}$ in diameter) elongated in the rolling direction. The austenite usually forms the islands in a ferritic phase.
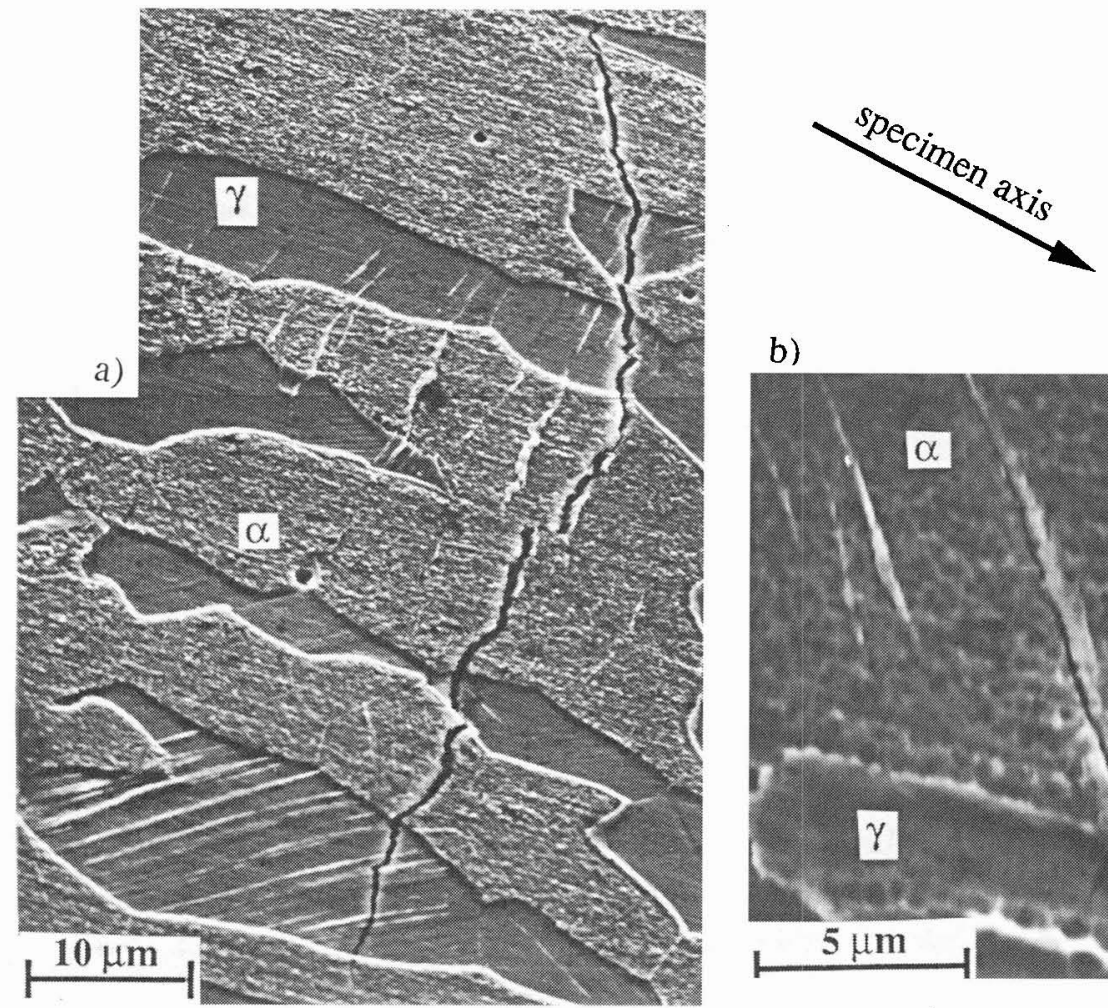

b)

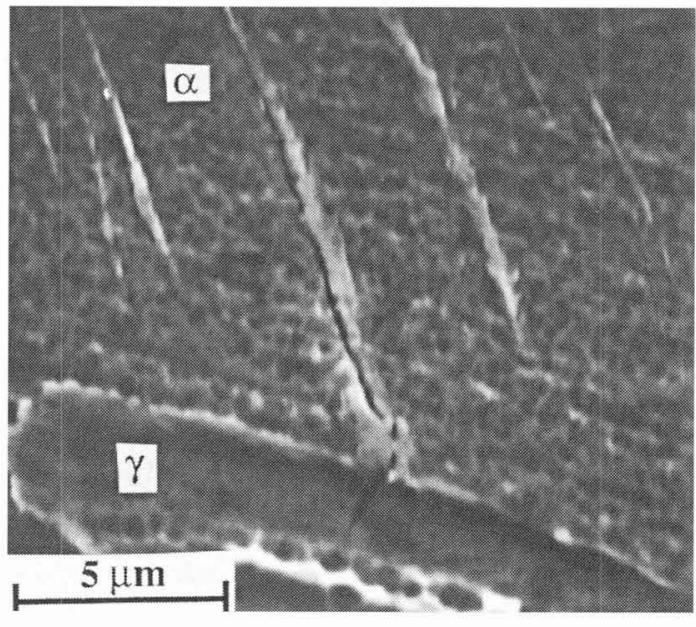

Fig. 9. Surface of the duplex stainless steel cycled with total strain amplitude $\varepsilon_{a}=4 \times 10^{-3}$ (SEM); $\varepsilon_{\text {aps }}=1.5 \times 10^{-3}$;

a) short fatigue crack initiated in the ferrite propagates across the ferrite and austenite islands.

b) early stage of the crack initiation along the PSB in a ferritic grain. 
The specimens made of the DIN X2CrNiMoN 22-5 duplex steel alloyed with $0.11 \mathrm{wt}$.\% of nitrogen were polished and etched to reveal both phases. They were subjected to symmetric constant strain amplitude cycling with different strain levels. The surface of a specimen at the half of the expected fatigue life is shown in Fig. 9. The overall picture (Fig. 9a) shows the shape of the ferritic $(\alpha)$ and austenitic $(\gamma)$ grains, the surface markings within the grains and a short crack crossing several grains. The surface markings, which indicate the presence of the bands of intensive cyclic slip - PSBs, are generally more numerous and more intensive in the ferritic grains. They appear in the form of extrusions egressing well above the original surface. Some of them are accompanied by intrusions, often hidden below the extrusions. The cracks nucleate usually along the PSBs in the ferrite as shown in Fig. 9b. Several parallel PSBs are present and only along one of them a nucleated crack can be identified. It grows into the neighbouring small austenitic grain. Slip markings in the austenitic grains (lower part of the Fig. 9a) are less intensive and hardly any primary crack in austenite was identified. This is due to the hardening of the austenite by the nitrogen. For low amplitude cycling, it results in the concentration of the plastic strain in the ferrite and earlier crack nucleation. The crack in Fig. 9a was nucleated in the ferrite grain along one of the PSBs and grew perpendicularly to the existing PSBs in the austenitic grain, though, in some other areas, the growth along the existing PSBs in the austenite was also observed.

Transmission electron microscopy study of ferritic and austenitic grains in fatigued duplex stainless steel [11] revealed features characteristic for slip intensification in localized volumina. The foils were cut parallel to the specimen axis and active slip plane was thus inclined at an angle equal or higher than $60^{\circ}$ to the foil plane. Fig. 10a shows the boundary between the matrix (lower part of the picture) and the area of the intensive slip - PSB (upper part of the picture) in the ferrite. The matrix consists of dislocation rich patches or bundles and channels between them with approximately equal volume fractions. The PSBs consist of thin dislocation walls and wide channels. The ratio of the volume occupied by the dislocation rich walls to the volume occupied by the channels is much smaller than in the matrix, usually $1 / 10$ up to $1 / 5$. In analogy with other materials, cyclic strain is concentrated into these bands which are parallel to the active slip plane.

The dislocation structure in an austenitic grain with characteristic structure corresponding to the localized plastic strain is shown in Fig. 10b. Two thin lamellae displayed in the micrograph in the form of ladders start to be formed in a generally irregular and mostly planar dislocation structure. In these lamellae, again thin dislocation walls and wide channels are present. The difference between the PSB structure and matrix structure is less pronounced in austenite than in ferrite. It corresponds to the less pronounced surface relief on the surface of austenitic grains and is connected with the lower plastic strain amplitude in the nitrogen hardened austenite.
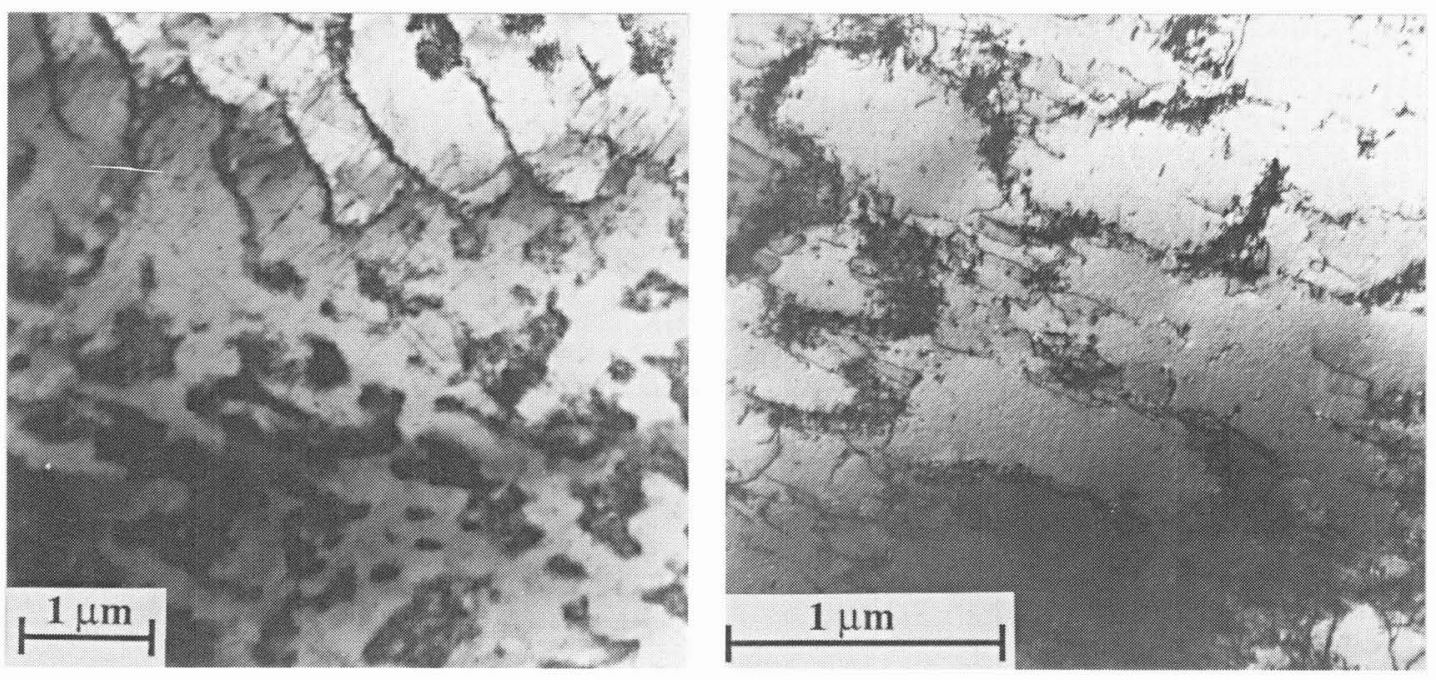

a)

Fig. 10. TEM micrographs of a duplex steel showing the structure corresponding to the cyclic strain localization. a) ferritic grain. b) austenitic grain. 


\section{Effect of slip localization on the crack nucleation}

Numerous examples of the surface relief and internal dislocation structures in several materials subjected to cyclic loading illustrate the intensive cyclic slip localization. Cyclic slip localization starts early in the fatigue life, before the cyclic stress amplitude saturates. The surface relief consisting of extrusions and intrusions is built up first. Several mechanisms of the surface relief formation due to localized intensive cyclic slip were proposed [10 - 12]. The intrusions which are formed during cyclic straining along the bands of intensive slip have important effect on the local slip intensification at the tip of intrusions and in the area between the regularly spaced semi-elliptic intrusions. The enhanced slip intensification and the slip irreversibility supported by the corrosive effect of environment was proposed [13] to be the reason for the nucleation of the shallow surface crack. Once the shallow surface crack is nucleated, it can grow by the same mechanism as that which is responsible for crack initiation with approximately constant growth rate. Later the effect of another strain intensification at the tip of the crack, which can be evaluated using fracture mechanics, becomes more important than the original irreversible slip and the crack accelerates. Since the initial crack growth rate represents the lowest crack growth rate in constant amplitude cycling, it is often life determining and, therefore, life estimations using the short crack growth data yield good life evaluation.

\section{Conclusions}

The experimental study of the surface relief formation, internal dislocation structures and cyclic stressstrain response in several classes of crystalline materials lead to the following conclusions:

(i) Repeated cyclic straining of materials results in most materials in stable cyclic stress-strain response which is the result of cyclic slip localization.

(ii) Specific dislocation configurations corresponding to localized cyclic slip are formed and can accommodate high local cyclic plastic strain.

(iii) Pronounced surface relief is formed where the thin lamellae of PSBs emerge on the surface consisting of extrusions and intrusions.

(iv) The surface relief enhances irreversible cyclic slip at the tip of intrusions and shallow surface cracks are nucleated.

(v) Areas of localized cyclic slip, nucleated shallow cracks, growing short cracks and finally the dominant crack represent a physical manifestation of the fatigue damage.

\section{References:}

[1] EWING J. A. and HUMFREY J. C. W., Philos. Trans. Royal Soc., London, A200 (1903) 241.

[2] FORSYTH P. J. E. , Nature 171 (1953) 172.

[3] POLÁK J., Cyclic Plasticity and Low Cycle Fatigue Life of Metals, Materials Science Monographs No. 63, Elsevier, Amsterdam, 1991.

[4] MUGHRABI H., Mater. Sci. Eng. 33.(1978) 207.

[5] POLÁK J., OBRTLÍK K. and HELESIC J., Mater. Sci. Eng. A 101 (1988) 7.

[6] ACKERMANN F., KUBIN L. P., LEPINOUX J. and MUGHRABI H., Acta Metall. 32 (1984) 715.

[7] POLÁK J., HELEŠIC J. and OBRTLÍK K., Magter. Sci. Eng. A132 (1991) 67.

[8] POLÁK J., OBRTLIKK K., HÁJEK M. and VASEK A., Mater. Sci. Eng. A151 (1992) 19.

[9] POLÁK J., Mater. Sci. Eng. 92 (1987) 71.

[10] DEGALLAIX G., SEDDOUKI A. and DEGALLAIX S., in Low Cycle Fatigue and Elasto-Plastic Behaviour of Materials - LCF3, K. T. Rie (Ed.), Elsevier, London, 1992, p. 76.

[11] POLÁK J., KRUML T. and DEGALLAIX S., Scripta Metall. Mater. - submitted for publication.

[12] ESSMANN U., GOSSELE U. and MUGHRABI H., Philos. Mag. A44 (1981) 405.

[13] POLÁK J. and LIŚKUTÍN P., Fatigue Fract. Eng. Mater. Struct., 13 (1990) 119. 